\title{
A Heterozygous Mutation in the Third Transmembrane Domain Causes a Dominant-Negative Effect on Signalling Capability of the MC4R
}

\author{
Patrick Tarnow $^{\mathrm{a}} \quad$ Anne Rediger ${ }^{\mathrm{a}} \quad$ Harald Brumm $^{\mathrm{a}}$ Petra Ambrugger ${ }^{\mathrm{a}}$ \\ Kurt Widhalm $^{\mathrm{b}} \quad$ Anke Hinney $^{\mathrm{c}} \quad$ Gunnar Kleinau $^{\mathrm{d}}$ Michael Schaefer $^{\mathrm{e}}$ Johannes Hebebrand ${ }^{\mathrm{c}}$ \\ Gerd Krause $^{d}$ Annette Grüters ${ }^{a}$ Heike Biebermann ${ }^{a}$

\begin{abstract}
a Department of Pediatric Endocrinology, Charité, Campus Virchow-Klinikum - Universitätsmedizin Berlin, Berlin, Germany
${ }^{b}$ Division of Nutrition and Metabolism, Department of Pediatrics, Medical University of Vienna, Austria

${ }^{c}$ Department of Child and Adolescent Psychiatry, University of Duisburg-Essen, Essen,

${ }^{\mathrm{d}}$ Leibniz-Institut für molekulare Pharmakologie (FMP),

e Neurowissenschaftliches Forschungszentrum, Bereich Molekulare Pharmakologie und Zellbiologie, Charité,

Campus Benjamin Franklin - Universitätsmedizin Berlin, Berlin, Germany
\end{abstract}

\section{Key Words}

MC4R · Mutation · Dominant-negative effect .

GPCR dimerization $\cdot \mathrm{H}$-bond network

\section{Summary}

Background: Heterozygous $M C 4 R$ mutation is the most frequent cause of monogenic obesity. For most MC4R mutations a gene dosage effect seems to be the underlying mechanism. However, a dominant negative effect of a heterozygous MC4R mutation was recently identified, pointing to an additional mechanism of MC4R inactivation. Methods: The complete loss-of-function mutation (Ser136Phe), identified in a cohort of obese Austrian patients, was characterized for cell surface expression, signal transduction and ligand binding properties. Co-transfection studies tested for a dominant negative effect. Dimerization was investigated by a sandwich ELISA and by fluorescence resonance energy transfer (FRET) approach. Potential intramolecular interactions of Ser136 were studied by homologous receptor modelling based on the crystal structure of the $\beta 2$-adrenergic receptor. Results: The Ser136Phe mutation showed a dominant negative effect. The sandwich ELISA and FRET approach demonstrated dimerization of mutant and wild type receptor. Receptor modelling revealed an essential function of Ser136 at transmembrane helix $3(\mathrm{TMH} 3)$ for establishing $\mathrm{H}$-bonds between $\mathrm{TMH} 2, \mathrm{TMH}_{3}$, and $\mathrm{TMH} 7$. The mutation Ser136Phe most likely disrupts this network and leads to an incompetent helix-helix arrangement in the mutated receptor. Conclusion: Identification of dominant negative MC4R mutations is important to fully understand receptor function and to determine receptor regions that are involved in MC4R dimer activation.

\section{Introduction}

Initially, frameshift mutations in the melanocortin 4 receptor $(M C 4 R)$ gene were found in two obese patients [1, 2]. To date the highest frequency of point mutations in extremely obese patients is found in the $M C 4 R$ gene, occurring in 1-5\% of obese patients $[3,4]$. The MC4R belongs to the large superfamily of G-protein-coupled receptors (GPCR) sharing the common structural feature of a seven-transmembranespanning protein [5]. The MC4R is activated by proopiomelanocortin(POMC)-derived peptides: $\alpha-\mathrm{MSH}$ and $\beta$-MSH. The activated receptor couples to the $\mathrm{G}_{\mathrm{s}}$ /adenylyl cyclase system, leading to decreased food intake and increased energy expenditure [6]. Targeted deletion of the MC4R resulted in severe obesity in homozygous mice while heterozygous female animals have an intermediate body weight [7]. These data clearly argue in favor of a gene-dosage effect of the $M C 4 R$ in weight homeostasis, which contrasts to known genotype-phenotype correlations of so far identified mutations in the GPCR gene family. However, in accordance to heterozygous mouse knock-out findings, most $M C 4 R$ mutations in obese humans were found in a heterozygous state. The resulting partial or complete loss-of-function of these mutant receptors implicated the same gene dosage effect on human weight maintenance as in rodents. So far a dominant negative effect for a variety of heterozygous $M C 4 R$ mutations was excluded $[8,9]$. However, we recently identified in an early-onset obese patient a heterozygous complete lossof-function mutation in transmembrane domain two (Asp90Asn) that results in high expression on the cell surface and binding of the ligand with the same affinity as the

\begin{tabular}{ll}
\hline KARGER & @ 2008 S. Karger GmbH, Freiburg \\
$\begin{array}{l}\text { Fax +497614520714 } \\
\begin{array}{l}\text { E-mail Information@Karger.de } \\
\text { www.karger.com }\end{array}\end{array}$ & $\begin{array}{l}\text { Accessible online at: } \\
\text { www.karger.com/ofa }\end{array}$ \\
&
\end{tabular}


wild type. In co-transfection studies of mutant and wild type receptor to resemble the situation in the patient we could show that the mutant receptors reduce the signalling capacity of the wild type receptor which could be classified as a dominant negative effect [10]. The identification of a dominant negative effect adds an additional mechanism how a heterozygous $M C 4 R$ mutation can result in severe earlyonset obesity.

Naturally occurring mutations in GPCRs are always a good target to get deeper information on structure and function, which is a prerequisite to understand the physiological role of the investigated receptor [11].

To understand the molecular mechanism of the dominant negative Asp90Asn mutation, we tested this receptor variant for oligomerization and demonstrated for the first time that the MC4R forms receptor homodimers.

It is now accepted that oligomerization of GPCR is one crucial feature to understand the complexity of GPCR function $[12,13]$. Currently many efforts are undertaken to understand how GPCR interaction occurs. Besides interactions via disulfide bridges, the relatively conserved transmembrane domains are highly suspicious for formation of interaction domains. However, to date only little is known about the involvement of single amino acids within the transmenbrane domains. Two single amino acids of the chemokine receptor CCR5 located in transmembrane domains 1 and 4 were found to be involved in dimerization [14]. Computational studies predict that transmembrane domains 5 and 6 and transmembrane domains 2 and 3 could form receptor-receptor interactions [15]. Mutations of single amino acids are thought to disrupt the dimerization interface by changing the hydrophobicity of the helices. Recently, calculation of ligand binding kinetics suggested existence of two tandemly arranged binding sites in a MC4R oligomer [16].

To fully understand MC4R function, it is of profound importance to know how interaction of wild type/wild type or wild type/mutant MC4R occurs. Recently we excluded the extracellular cysteine residues of the MC4R as interaction partners [17]. Dominant negative effects of naturally occurring $M C 4 R$ mutations point towards receptor regions holding the receptor/receptor complex in an inactive state.

The heterozygous mutation in the $M C 4 R$, Ser136Phe, was found in a 2.3-year-old girl with severe obesity (BMI $33.2 \mathrm{~kg} / \mathrm{m}^{2},>99$ th centile), hyperphagia and asymmetry of the amygdaloid nuclei [18]. Her 18-year-old sister and her 53-yearold grandmother were also heterozygous mutation carriers and obese (BMI 33.4 and $41.7 \mathrm{~kg} / \mathrm{m}^{2}$, respectively). Affected male family members as the 17 -year-old brother and the 35 year-old father had BMI of 25.6 and $30.7 \mathrm{~kg} / \mathrm{m}^{2}$ but are reported to have a higher body weight in the past (for detailed information see supplemental data). Here we report a new case of a heterozygous dominant negative $M C 4 R$ mutation in transmembrane domain 3 (Ser136Phe) found in a family with extreme early-onset obesity.

\section{Material and Methods}

\section{Functional Studies}

Wild type as well as mutant $\mathrm{S} 136 \mathrm{~F} M C 4 R$ were cloned in a pcDps expression vector. For functional studies mutant and wild type receptors were transiently transfected into COS-7 cells using Metafectene ${ }^{\mathrm{TM}}$ (Biontex, Munich, Germany) according to the manufacturers protocol. $72 \mathrm{~h}$ later cAMP accumulation assays were performed as described previously [19]. For co-transfection equal amounts ( $3 \mu \mathrm{g}$ each per 12-well plate) of wild type and mutant receptor or monocarboxylate transporter 8 (MCT8) as negative control were used.

For cell surface binding studies cells were transfected with Metafectene in 48-well plates. Two days later cells were incubated overnight with increasing amounts of $\alpha-\mathrm{MSH}$ and constant amounts of ${ }^{125}$ I-labeled NDP-alphaMSH. After washing specifically bound ${ }^{125} \mathrm{I}-\mathrm{NDP}$-alpha-MSH was measured.

To investigate cell surface expression, wild type and mutant cells were Nterminally HA-tagged and tested in cell surface ELISA studies. $48 \mathrm{~h}$ after transfection cells were paraformaldehyde-fixated, and the extracellular HA epitope was probed with a biotin-labelled antibody (Roche Applied Science; Mannheim Germany). Bound anti-HA antibody was detected by peroxidase-labelled streptavidin (Dianova, Hamburg, Germany) in a substrate/chromogen reaction as described [20].

For investigation of receptor dimerization a sandwich ELISA was performed with aminoterminal HA-tagged (N-HA) and carboxyterminal FLAG-tagged (C-FLAG) constructs.

Plasmids were co-transfected in 6-cm dishes. As negative controls a HAtagged thyroid hormone tranporter (MCT8) was co-transfected with MC4R-C-Flag or the N-HA-MC4R construct was transfected alone. $48 \mathrm{~h}$ after transfection, cells were harvested and solubilized overnight. The lysates were incubated in anti-FLAG antibody-coated 96-well plates (Sigma-Aldrich, Hamburg, Germany) for $2 \mathrm{~h}$. Detection of the HA epitope was performed as described above.

For statistical analysis we conducted a one-way ANOVA to investigate global differences between the dimerization of the negative control WTMC4R-CFL+WTMCT8-NHA and the mutant S136F-NHA+ WTMC4R-CFL, followed by subsequent Tukey tests for the post-hoc comparisons between the negative control and the different constructs. The tests were performed with SPSS 12.0 (Munich, Germany).

By fluorescence resonance energy transfer (FRET) we are able to directly demonstrate dimerization in living cells. For FRET analysis MC4R-WT and S136F mutants were C-terminally fused to cyan (CFP) or yellow (YFP) fluorescent protein using the EcoRI and $K p n I$ sites of pECFP-N1 or pEYFP-N1 vectors (Clontech, Palo Alto, CA, USA). HEK293 cells were transiently co-transfected with various amounts of resulting plasmids encoding a CFP- and a YFP-fused receptor using the FuGENE 6 transfection reagent (Roche Molecular Biochemicals, Mannheim, Germany; $4 \mu \mathrm{l}$ of FuGENE 6 / $2 \mu \mathrm{g}$ of DNA). Cells were grown on glass cover slips, which were treated with $0.01 \mathrm{mg} / \mathrm{ml}$ poly-L-lysine (Biochrom, Berlin Germany), for $48 \mathrm{~h}$. Cover slips were then mounted in a custom-mode chamber of an inverted microscope with a Plan-Apochromat $63 \times / 1.4 \mathrm{ob}-$ jective (Axiovert 100; Carl Zeiss Microimaging, Jena, Germany) and covered in a Hepes-buffered solution $(138 \mathrm{nmol} / 1 \mathrm{NaCl}, 6 \mathrm{mmol} / \mathrm{l} \mathrm{KCl}$, $1 \mathrm{mmol} / 1 \mathrm{MgCl}_{2}, 1 \mathrm{mmol} / \mathrm{l} \mathrm{CaCl}$, $5.5 \mathrm{mmol} / 1$ glucose, $2 \mathrm{mg} / \mathrm{ml}$ bovine serum albumin, and $10 \mathrm{mmol} / \mathrm{l}$ Hepes, $\mathrm{pH}$ 7.5) for the whole measurement. Measurement instructions are already described by Brock et al., [41]. Briefly, CFP and YFP were alternately excited at 440 and $510 \mathrm{~nm}$ with a monochromator (PolychromeII; TILL Photonics, Gräfelfing, Germany). The use of a motorized filter wheel (Lambda 10/2; Sutter Instrument Company, Novato, CA, USA) permits the separate detection (cooled CCD camera; IMAGO, TILL Photonics) of the emitted light through different band pass filter (460-500 nm for CFP and 535-580 nm for YFP). FRET was investigated as the recovery of CFP (donor) fluorescence during YFP (acceptor) bleach. First, CFP and YFP fluorescences 
Table 1. Functional characterization of S136F MC4R in comparison to wild type receptor, the wild type receptor co-expressed with the S136F mutant and the wild type receptor co-expressed with MCT8 as negative control based on ligand-induced cAMP production and cell surface expression ${ }^{\mathrm{a}}$

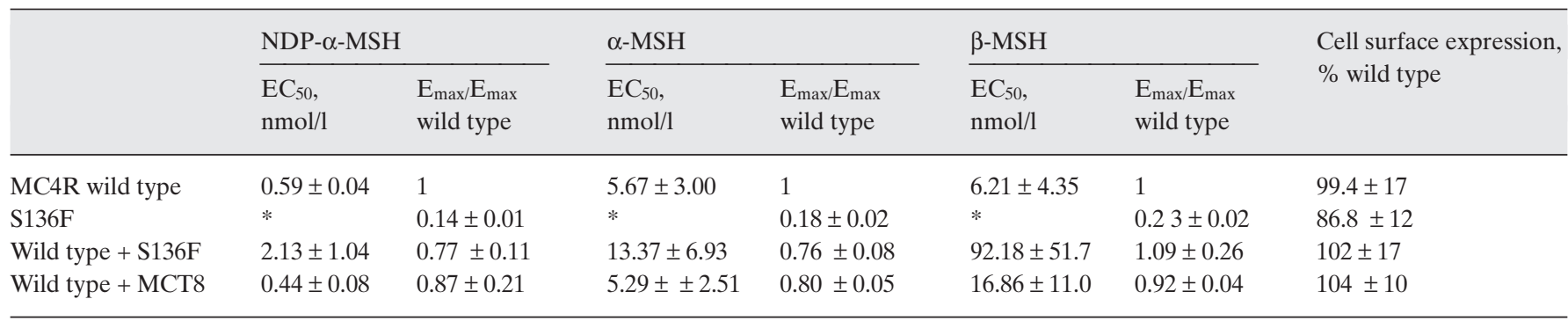

${ }^{a} \mathrm{EC}_{50}$ and $\mathrm{E}_{\max }$ values were obtained using the computer program GraphPadPrism. Data represent means \pm S.E.M derived from at least three independent experiments each performed in duplicates in cAMP assays or hexplicates in case of cell surface ELISA. Range of wild type Emax was between 1,807 and 5,706 cpm. Optical density of wild type MC4R in ELISA studies ranged between 0.53 and 0.86.

*Not determinable due to low maximal stimulation.

without acceptor bleach were recorded during 30 cycles with a 10-20 ms exposure. Then, 60 cycles were recorded with an additional 2-s illumination per cycle at $512 \mathrm{~nm}$ to bleach YFP.

$A$ homologous molecular monomer model of the serpentine domain of the MC4R which is based on the recently solved X-ray structures of the $\beta 2$-adrenergic receptor ( $\beta 2$-AR) $[21,22]$ (protein data bank (PDB) entry codes: 2RH1, 2R4R) was generated with Sybyl 7.3.5 (Tripos, St. Louis, MS, USA). However, several MC4R-specific corrections were made, such as regular helix extensions in transmembrane helix 2 (TMH2) and TMH5 of the MC4R instead of structural bulges in the two helices of $\beta 2-\mathrm{AR}$. The major structural difference concerns extracellular loop two (ECL2). The ECL2 of the MC4R which connects TMH4 and TMH5 consist only four amino acids. Therefore, the ECL2 of the $\beta 2$-AR was substituted by a short loop conformation of the MC4R. Loops were refined by best fit and homology to fragments of other proteins from PDB. Gaps of missing residues in the loops of the template structure were closed by the 'Loop Search' tool implemented in Sybyl 7.3.5. Conjugate gradient minimizations were performed until converging at a termination gradient of $0.05 \mathrm{kcal} /(\mathrm{mol} \times \AA)$ using the AMBER 7.0 force field [23]. Quality and stability of the model were validated by checking the geometry by PROCHECK (www.biochem.ucl.ac.uk/ roman/procheck/procheck.html) [24] and by monitoring the root mean square deviation (RMSD) during a molecular dynamics simulation of $4 \mathrm{~ns}$.

\section{Results}

To investigate functional properties of the Ser136Phe mutant, $M C 4 R$ COS-7 cells were transiently transfected with wild type and mutant $M C 4 R$ constructs. First, in cell surface expression studies of the mutant receptor we observed that the Ser136Phe mutant only shows a slight reduction of cell surface expression compared to the wild type receptor (table 1), which was not significant $(\mathrm{p}>0.05)$. Second, investigation of signal transduction properties of the mutant S136F receptor revealed a complete loss of adenylyl cyclase activation after stimulation with the natural MC4R ligands $\alpha-\mathrm{MSH}$ and $\beta$-MSH as well as with the highly potent artificial ligand NDP- $\alpha$-MSH (table 1, fig. 1a). Third, binding properties of wild type and mutant receptor are comparable (fig. 1b).
The functional characteristics of a complete loss-of-function $M C 4 R$ mutation highly expressed on the cell surface with ligand-binding properties comparable to the wild type receptor is in accordance with the functional situation of the heterozygous D90N mutation where we demonstrated a dominant negative effect [10].

Consequently, we performed co-transfection studies with wild type and S136F mutant MC4R and as control with the thyroid hormone transporter MCT8. We investigated signal transduction properties after stimulation with the natural ligands $\alpha$ $\mathrm{MSH}$ and $\beta-\mathrm{MSH}$ as well as NDP- $\alpha-\mathrm{MSH}$. The mutant receptor exhibited a dominant negative effect on wild type receptor function by increasing $\mathrm{EC}_{50}$ values by a factor of approximately 3 after stimulation with NDP- $\alpha-\mathrm{MSH}$ and $\alpha$-MSH and of 14 after stimulation with $\beta$-MSH (table 1 , and fig. 1a). This effect was significant for the stimulation with $\beta$-MSH when the $\mathrm{EC}_{50}$ values of the wild type/mutant co-transfection were compared with those of the single transfected wild type MC4R or the MC4R/MCT8 co-transfection $(\mathrm{p}<0.05)$. Additionally we performed experiments in $\mathrm{CHO}$ cells that stably express the wild type MC4R and co-transfected the S136F mutant to ensure that obtained data were not a result of an artificial over-expression system. Again, the S136F mutant showed a dominant negative effect on wild type receptor function (data not shown).

Recently, we showed that the wild type MC4R as well as wild type and non-synonymously mutant D90N-MC4R are able to form receptor oligomers [10]. To test this functional characteristic of the MC4R for the S136F mutant, we applied a sandwich ELISA approach with differentially tagged receptors (Nterminally HA or C-terminally FLAG) after co-transfection of wild type and mutant receptor. In comparison to negative controls (transfection of wild type MC4R-N-HA alone or cotransfection of wild type MC4R and MCT8) wild type MC4R and S136F mutants formed receptor oligomers to the same extent as the wild type MC4R (fig. 1c). In comparison to the neg- 


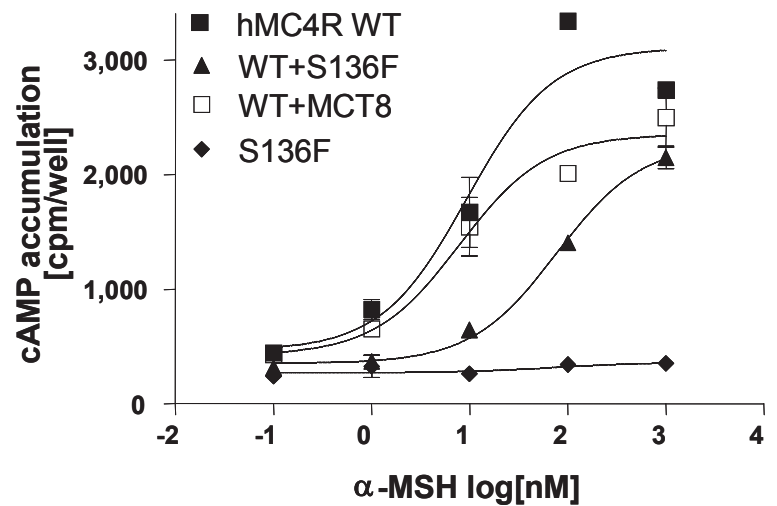

a

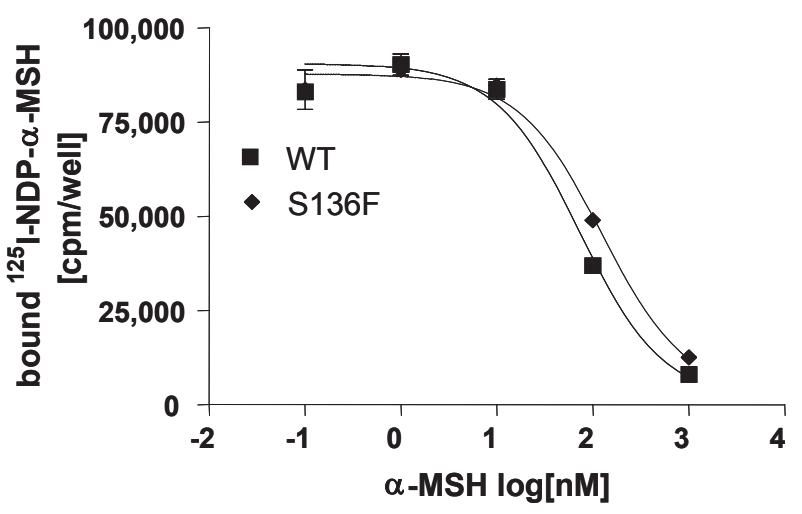

C

Fig. 1. Functional characteristics of the MC4R S136F mutant: Assays were performed $48 \mathrm{~h}$ after transfection of WT and mutant constructs into COS7 cells. a cAMP accumulation after stimulation with different concentrations of $\alpha-\mathrm{MSH}$. Co-transfection of WT MC4R and thyroid hormone transporter MCT8 served as negative control. One representative experiment out of four performed in duplicates is shown. b Binding of ${ }^{125} \mathrm{I}$ - NDP- $\alpha$-MSH and displacement by $\alpha-\mathrm{MSH}$. $\mathrm{B}_{\max }$ of ${ }^{125} \mathrm{I}-\mathrm{NDP}-\alpha-\mathrm{MSH}$ at the WT MC4R was $91874.5 \pm 6718$ and at S136F mutant $87839 \pm 3809$ $\mathrm{cpm}$. Displacement with unlabeled $\alpha$-MSH resulted in $\mathrm{IC}_{50}$ values of 70.3 \pm 11.64 and $125.7 \pm 21.07$ of WT and mutant MC4R, respectively. IC $C_{50}$ values were obtained using GraphPadPrism software. c Investigation of dimerization of the mutant S136F by a sandwich-ELISA approach. COS-7

ative control (wild type MC4R-CFL + wild type MCT8-NHA) all tested constructs differed significantly in their optical density $(\mathrm{p}<0.001)$. No difference in the optical density of dimers was visible between the wild type MC4R-NHA + wild type MC4R-CFL and the mutant MC4R-S136F-NHA +wild type MC4R-CFL $(\mathrm{p}<0.05)$.

The results of FRET analysis support our data of the sandwich ELISA. To prove the formation of dimers in the plasma membrane of intact HEK293 cells by photobleaching FRET, wild type MC4R and S136F mutant were C-terminally fused to different fluorophores (CFP and YFP). We obtained consistent FRET efficiencies between 17.3 and $16.9 \%$ for the wild type MC4R-CFP + wild type MC4R-YFP and the mutant MC4RS136F-YFP + wild type MC4R-CFP (fig. 2A,B). As

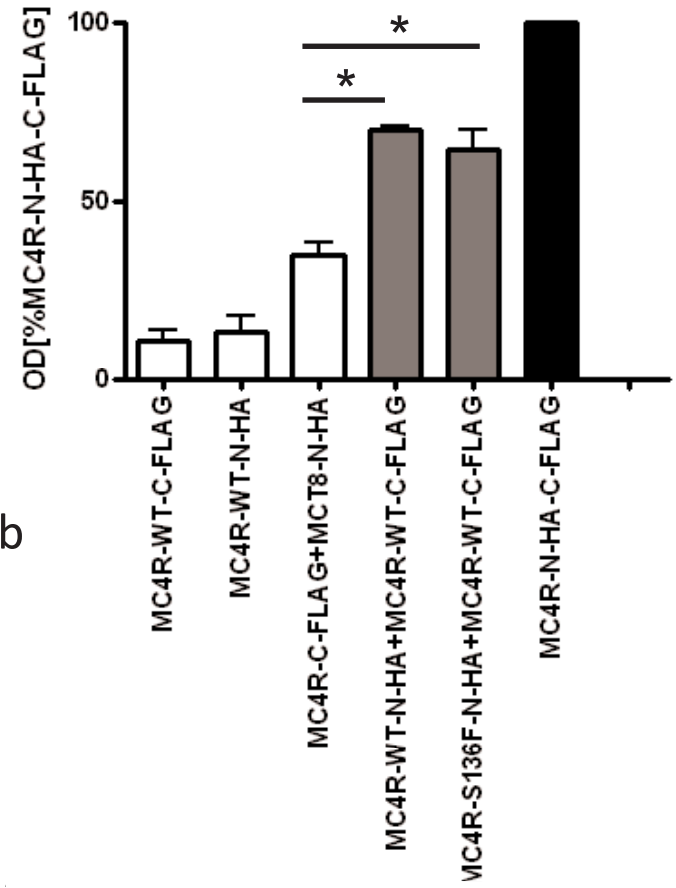

cells were co-transfected with differentially tagged MC4R constructs, solubilized overnight and incubated in FLAG-antibody-coated 96-well plates. Dimerization was measured via the N-terminally tagged HA epitope as increase in optical density. WT-MC4R-CFL, WT-MC4R-NHA and co-transfected with WT-MC4R-C-FLAG with MCT8-N-HA served as negative controls, double tagged MC4R and co-transfection of WTMC4R-N-HA and WT-MC4R-C-FLAG were used as positive controls. The mean absorption $(492 \mathrm{~nm} / 620 \mathrm{~nm})$ is shown as percentage of the double tagged WT-MC4R of three independent experiments. One way ANOVA and Tukey tests were conducted for the difference of the negative control (WT-MC4R-CFL+WT-MCT8-NHA) and two constructs $(\mathrm{p}<0.001)$.

negative control dimerization between the MC4R and the cannabinoid receptor type 1 (CB1R) was tested (fig. 2C). In this experiments a FRET efficency of $5.85 \%$ was obtained, indicating absence of dimerization.

The molecular monomer model of the MC4R reveals that S136 at TMH3 is located in the same structural microdomain as D90 in TMH2, and N294, D298 in TMH7 (fig. 3). They interact via $\mathrm{H}$-bonds under assistance of four water molecules, which are conserved at identical locations in the $\beta 2-\mathrm{AR}$ and in the bovine rhodopsin crystal structures as well. This H-bond network is essential for constraining the transmembrane helix arrangement in the basal signalling-competent conformation. In conclusion, we report the second heterozygous complete loss-of-function $M C 4 R$ mutation causing a dominant negative 


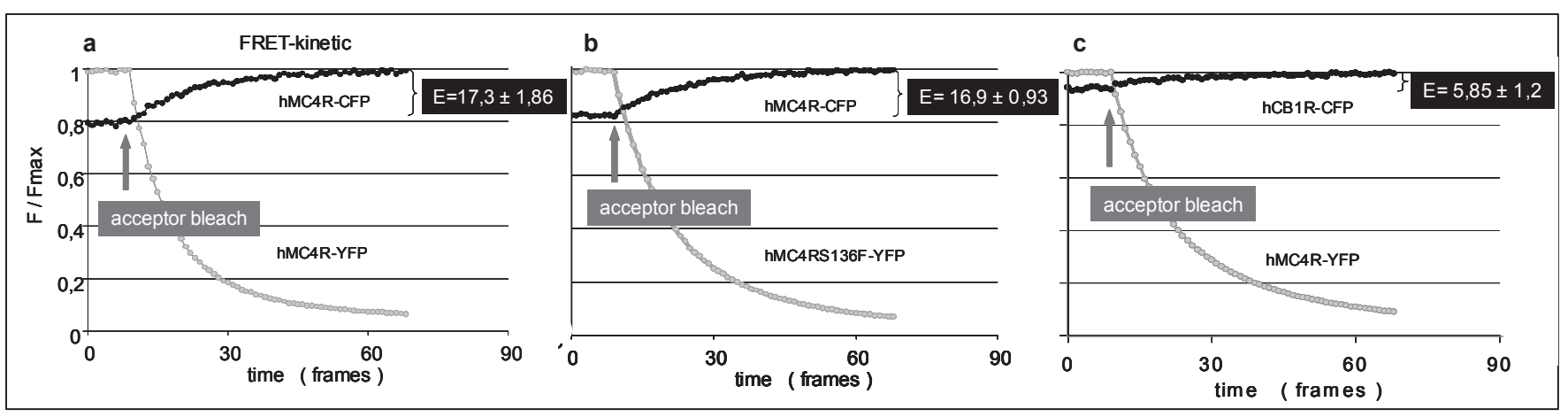

Fig. 2. FRET analysis of living HEK 293 cells transiently co-transfected with human WT MC4R, the S136F mutant or CB1R. HEK293 cells were co-transfected with plasmids encoding $\mathbf{a}$ WT-MC4R-CFP and WT-MC4RYFP, b WT-MC4R-CFP and the mutant MC4R-S136F-YFP or $\mathbf{c}$ CB1RCFP and WT-MC4R-YFP as negative control.

If protein-protein interaction takes place, the two fluorophores CFP and YFP are in close proximity $(<100 \AA)$. In this case excitation of CFP (donor) allows energy transfer to YFP (acceptor) and emission light of a characteristic wavelength are detectable.

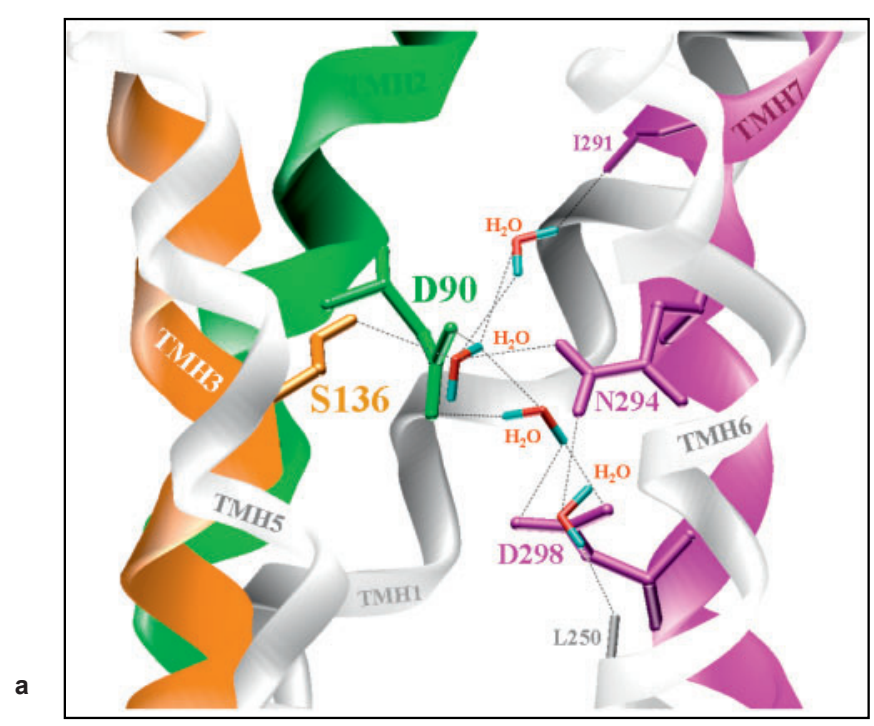

Fig. 3. Three dimensional molecular monomer model of the MC4R. Molecular homology model of the serpentine domain of the MC4R was generated based on the recently solved X-ray structure of the $\beta 2$-adrenergic receptor [21, 22]. Amino acids D90, S136, N294, and D298 at TMH2, TMH3, and TMH7 are located in a common structural microdomain.

effect on signalling capability. The mutant receptor is able to dimerize with the wild type receptor in a manner the wild type receptor dimerizes with itself.

The side chain of S136 is involved in an interhelical H-bond network constraining the signalling-competent basal conformation of the wild type receptor. The pathogenic mutation $\mathrm{S} 136 \mathrm{~F}$ leads to disruption of these stabilizing interactions and finally causes a signalling-incompetent arrangement of the signalling-essential transmembrane helices 2,3, and 7 .
Here, FRET signals are detected by recording the donor recovery (CFP emission, black line) before and during acceptor bleaching (YFP emission, gray line). The selective photobleaching at $512 \mathrm{~nm}$ results in a decrease in YFP emission accompanied by an increase in CFP emission. An increase in CFP fluorescence during YFP-bleach is direct evidence for FRET. FRET efficiencies $E$ were calculated from the relative increase in CFP emission and the decrease in YFP emission by linear regression. The depicted data represent means \pm SEM of 4-6 single cells of one representative measurement of at least three independent transfection experiments performed in triplicates.

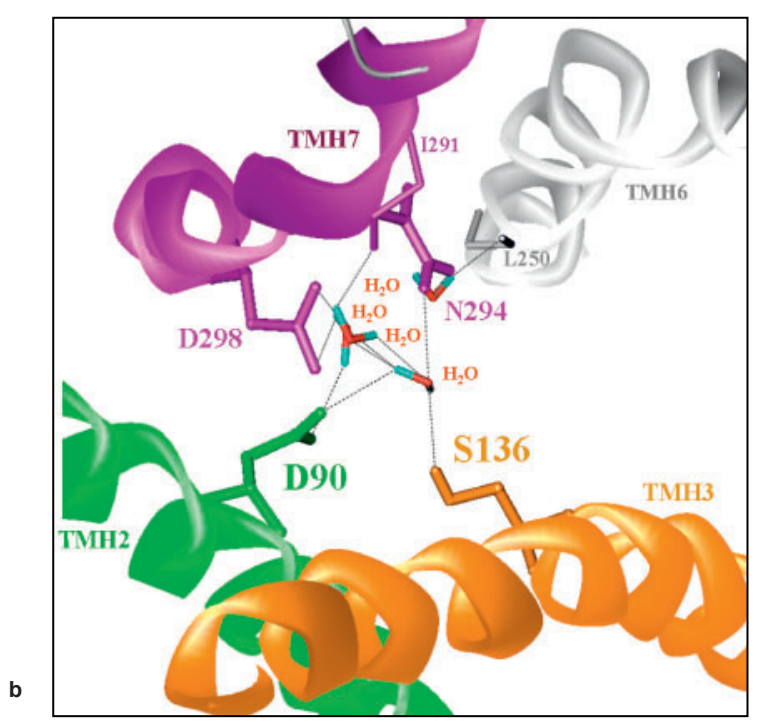

They interact via H-bonds under assistance of four water molecules (conserved in X-ray structures of bov rhodopsin and $\beta 2$-adrenergic receptor). This H-bond network is essential for constraining the transmembrane helix arrangement in the basal signalling-competent conformation.

\section{Discussion}

We have demonstrated a dominant negative effect of a naturally occurring $M C 4 R$ mutation on the wild type receptor. (For information on the phenotype of the mutation carrier and family please see supplementary material). Prerequisite for this effect seems to be a strong expression of the mutated receptor on the cell surface and potent ligand binding properties as well as the ability to form heterodimers with wild type receptors. 


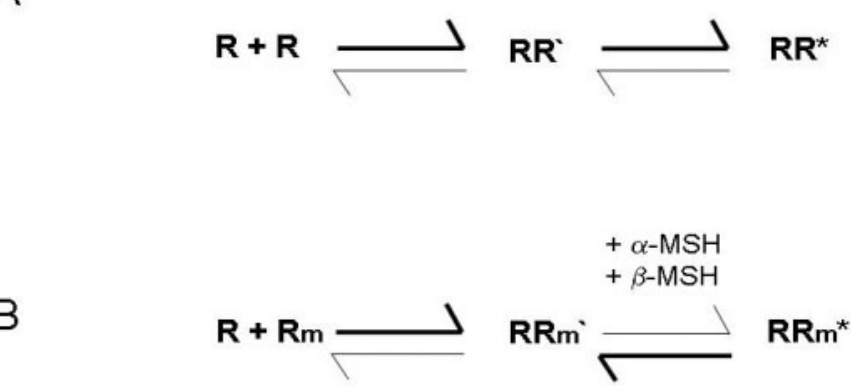

Fig. 4. Theoretical model of MC4R dimer activation. $\mathrm{R}$ represents the MC4R monomer, RR the MC4R dimer and RR* the activated state of the dimer. A In case of MC4R-WT homo-dimerization or dimerization of WT-MC4R with a mutant MC4R that does not cause a dominant negative effect ligand stimulation result in a shift of the equilibrium to the activated state RR* that allows efficient coupling to the Gs/adenylyl cyclase pathway. B In case of MC4R dimerization with a dominant negative mutant receptor $(\mathrm{Rm})$ the receptor dimer is trapped in the inactive state in which a shift to the activated state is alterated.

In most cases $M C 4 R$ mutations occur heterozygously. These heterozygous mutation carriers are up to two SD scores heavier than their wild type family members [25].

Heterozygous $M C 4 R$ mutations causing a dominant negative effect seem to be rare. For a variety of heterozygous complete and partial loss-of-function $M C 4 R$ mutations a dominant negative effect seemed to be excluded $[8,9,17]$. For these mutations a gene dosage effect might be the underlying molecular mechanism. Homozygous or compound heterozygous $M C 4 R$ mutations are as rare as homozygous recessive mutations in other genes of the leptinergic-melanocortinergic pathway, e.g. leptin or POMC mutations [3,26-31]. The degree of obesity in these homozygous or compound heterozygous $M C 4 R$ mutation carriers seems to be more extreme than in heterozygous mutation carriers $[3,27,28]$. One might assume that the phenotype of patients with a dominant negative $M C 4 R$ mutation might be intermediate between homozygous/compound heterozygous and heterozygous carriers of haploinsufficiency mutations. However, due to the detection of only two dominant negative mutations so far, this hypothesis will remain a mere speculation until more such mutations are identified. Additionally we have to take into account that not only the dominant negative effect but also additional factors play a role in the phenotypic appearance of obesity, e.g. the gender or the age of the mutation carrier.

The finding that the MC4R is able to form receptor oligomers adds one important functional characteristic to the understanding of its function in weight regulation. GPCR homo- or hetero-oligomerization as an important functional characteristic, and is now an accepted feature of GPCRs [12.13]. We tested dimerization of the heterozygous partial loss-of-function Ser127Leu mutation also located in transmembrane domain 3. This mutation forms a dimer with the wild type receptor but the mutation does not have a dominant negative effect on wild type receptor function [17]. Hence, only specific $M C 4 R$ mutations like D90N or S136F are able to keep the wild type/mutant dimer in an inactive state in the presence of ligand (fig. 4). From these findings we conclude that receptor dimerization is a complex mechanism in which the association of transmembrane domains as well as single amino acids may be involved. In view of the complex ternary model of receptor activation [32] the MC4R dimers (wild type/wild type or wild type/ mutant) will be activated by natural or artificial ligands and the equilibrium is pushed to an active state. If a specific $M C 4 R$ mutation that does not abolish receptor dimerization is able to keep the receptor complex in an inactive state even after ligand stimulation, a dominant negative effect occurs. So far this could only be observed for the D90N and the S136F mutations. These amino acid positions seem to play an important role in receptor oligomer activation. The position of D90 in transmembrane domain 2 is the most conserved position in all GPCRs. If this position is mutated, the $\mathrm{EC}_{50}$ value for wild type mutant activation is shifted towards higher agonist concentrations by a factor of approximately 100 . This could not be detected for co-expression with the Gs-coupling TSHR [10]. Ser136 in transmembrane domain 3 is located in a stretch of four serine residues. Mutation of S136 to phenylalanine resulted in a shift by the factor of 3-14 towards higher ligand concentration for activation of the wild type/mutant complex.

The molecular monomer model of the MC4R reveals an intramolecular H-bond network between the transmembrane helices TMH2, TMH3, and TMH7, wherein the side chain of S136 is involved. Water molecules which are highly conserved in the available crystal structures of rhodopsin [33-35] and the $\beta 2-\mathrm{AR}[21,22]$ are assisting this H-bond network. This network in the MC4R is essential for constraining the transmembrane helix arrangement in the basal signalling-competent conformation. Substitution of the hydrophilic serine side chain by the bulky aromatic side chain moiety of the phenylalanine in the S136F mutation most likely disrupts observed interaction by hydrophobic repulsion and sterical disarrangement between the interacting partners. This finally leads to an incompetence of the mutated receptor to transduce the ligand-initiated signal by distinct rearrangement of the transmembrane helix bundle towards the G-protein coupling interface. This scenario is supported by following facts: i) Previous mutant D90N showed similar dominant negative effect as the S136F mutant investigated here. ii) Together with N294 and D298 in TMH7, and D90 in TMH2, S136 in TMH3 are critical residues of the intramolecular H-bond network, and they are iii) completely conserved among over $70 \mathrm{MC} 4 \mathrm{R}$ orthologs [36]. Moreover, the stabilizing interactions between the transmembrane helices in the structural microdomain suggested for the MC4R, are also reported at corresponding positions for other GPCRs [37]. Since both side chains of D90 and S136 are oriented towards the interior portion of the MC4R monomer model, they are very likely not directly involved in potential
160

Obesity Facts 2008;1:155-162
Tarnow/Rediger/Brumm/Ambrugger/ Rettenbacher/Widhalm/Hinney/Kleinau/ Schaefer/Hebebrand/Krause/Grüters/ Biebermann 
dimer interaction of MC4R. One can only speculate that they exert an indirect effect via the H-bond network on the arrangement of the transmembrane helices and therewith likely also indirect effects on the oligomer activation.

All EC $\mathrm{E}_{50}$ enhancements clearly exceeding 2 (which is the case for binding the ligand by a mutant receptor without receptor activation) could be classified as a dominant negative effect. Notably, the highest shift in $\mathrm{EC}_{50}$ values is found after cotransfection of wild type and mutant receptor and upon stimulation with $\beta$-MSH. Under the assumption that $\beta$-MSH rather then $\alpha-\mathrm{MSH}$ is responsible for hypothalamic weight regulation [38-40], a shift of a factor of $>10$ may explain the severe phenotype of the patient.

In this study we report the second $M C 4 R$ mutation showing a dominant negative effect on wild type receptor signalling function. The identification of $M C 4 R$ mutations that have a dominant negative effect, in contrast to those mutations for which the underlying molecular mechanism is a gene dosage effect, will help to identify those receptor regions that are essential to switch the MC4R conformation between the basal and activated state.

\section{Appendix}

\section{Description of the Index Patient and Her Family}

The S136F mutation was found in a girl aged 2 years and 4 months. The patient is the third child of three siblings born of non-consanguineous parents of Serbian descent. The weight of the index patient was $30.3 \mathrm{~kg}$ ( $>99$ th centile), height was $95.5 \mathrm{~cm}$ ( $>97$ th centile), resulting in a body mass index (BMI) of $33.2 \mathrm{~kg} / \mathrm{m}^{2}$ ( $>99$ th centile). Blood pressure was $86 / 75$ $\mathrm{mm} \mathrm{Hg}$. Her birth weight was 4,190 g and excessive weight gain started before two month of age. She weighed $16 \mathrm{~kg}$ at 10.5 months of age and $27.5 \mathrm{~kg}$ at 2 years of age. Her parents reported marked hyperphagia with constant food seeking, similar to previously described persons carrying a mutated MC4R $[1,3]$. A magnetic resonance imaging (MRI) of the CNS of the patient showed an asymmetry of the amygdaloid nuclei [18]. On laboratory testing her fasting blood glucose was 5.1 (reference value 3.3-6.1) mmol/l; TSH, $3.59(0.85-6.50) \mu \mathrm{U} / \mathrm{ml}$; free T4, 1.51 (0.90-1.70) $\mathrm{ng} / \mathrm{dl}$; total cholesterol, 139 (100-200) mg/dl; high-density lipoprotein cholesterol, 44 (>40) mg/dl; low-density lipoprotein cholesterol, 74 (>125) $\mathrm{mg} / \mathrm{dl}$; and triglycerides, $107(35-150) \mathrm{mg} / \mathrm{dl}$. An OGTT was performed 8 months later. Fasting blood glucose was $3.27(3.2-5.6) \mathrm{mmol} / \mathrm{l}$, fasting insulin $8.20(3.0-15.0) \mathrm{mU} / \mathrm{l}$, resulting in an insulin resistance index of $1.19(<3.2) \mathrm{mmol} / \mathrm{l} \times \mathrm{mU} / \mathrm{l}$.

All available relatives of the index patient were genotyped. Only the mother, who is also severely obese (BMI $35.5 \mathrm{~kg} / \mathrm{m}^{2},>99$ th centile) did not carry the S136F mutation. All other family members were heterozygous mutation carriers: the paternal grandmother (BMI $41.7 \mathrm{~kg} / \mathrm{m}^{2},>99$ th centile), the father (BMI $30.7 \mathrm{~kg} / \mathrm{m}^{2}$, 96th centile), the elder sister (BMI 33.4 $\mathrm{kg} / \mathrm{m}^{2},>99$ th centile) and the elder brother (BMI $25.6 \mathrm{~kg} / \mathrm{m}^{2}, 94$ th centile). All mutation carriers have a similar weight history. For all early onset of obesity with abnormal weight gain in the first year of life was reported. Concerning the father and particularly the brother of the index patient, the obese phenotype became less apparent in adult age. The father aged 35 years weighs $95 \mathrm{~kg}$ at a height of $1.76 \mathrm{~m}$ which results in a BMI of 30.7 $\mathrm{kg} / \mathrm{m}^{2}$ (96th centile). His maximum weight was $112 \mathrm{~kg}$. The brother of the index patient had a maximum weight of $115 \mathrm{~kg}$ at the age of 14 years, and at the time of this study weighed $81 \mathrm{~kg}$ (BMI $25.6 \mathrm{~kg} / \mathrm{m}^{2}, 94 \mathrm{th}$ centile) at the age of 17. The current weight of the 18 year old sister was $100 \mathrm{~kg}$ (BMI $33.4 \mathrm{~kg} / \mathrm{m}^{2},>99$ th centile). She reported a maximum weight of $120 \mathrm{~kg}$ at the age of 17. The paternal grandmother had a weight of $104 \mathrm{~kg}$ (BMI $41.7 \mathrm{~kg} / \mathrm{m}^{2},>99$ th centile). She is under medical treatment for hypertension. The paternal grandfather and maternal grandparents were not available for phenotypic characterization, but according to reports of the available family members they all had been overweight or even obese.

\section{Acknowledgements}

The authors thank Anna-Maria Werner for skilful technical assistance. This work was supported by the Deutsche Forschungsgemeinschaft, SFB 577 TP A9, the graduate college 1208 and the Bundesministerium für Bildung und Forschung (BMBF) NGFN-2 01GS0482/TP1 and 01GS0492/TP13.

\section{References}

$>_{1}$ Yeo GS, Farooqi IS, Aminian S, Halsall DJ, Stanhope RG, O'Rahilly S: A frameshift mutation in MC4R associated with dominantly inherited human obesity. Nat Genet 1998;20:111-112.

2 Vaisse C, Clement K, Guy-Grand B, Froguel P: A frameshift mutation in human MC4R is associated with a dominant form of obesity. Nat Genet 1998; 20:113-114.

3 Farooqi IS, Keogh JM, Yeo GS, Lank EJ, Cheetham T, O'Rahilly S: Clinical spectrum of obesity and mutations in the melanocortin 4 receptor gene. $\mathrm{N}$ Engl J Med 2003;348:1085-1095.

4 Hinney A, Bettecken T, Tarnow P, Brumm H, Reichwald K, Lichtner P, Scherag A, Nguyen TT, Schlumberger P, Rief W, Vollmert C, Illig T, Wichmann HE, Schäfer H, Platzer M, Biebermann H, Meitinger T, Hebebrand J: Prevalence, spectrum, and functional characterization of melanocortin-4 receptor gene mutations in a representative population-based sample and obese adults from Germany. J Clin Endocrinol Metab 2006;91:1761-1769.
5 Gantz I, Miwa H, Konda Y, Shimoto Y, Tashiro T, Watson SJ, DelValle J, Yamada T: Molecular cloning, expression, and gene localization of a fourth melanocortin receptor. J Biol Chem 1993; 268:15174-15179.

6 Cone RD: Anatomy and regulation of the central melanocortin system. Nat Neurosci 2005;8:571-578.

7 Huszar D, Lynch CA, Fairchild-Huntres V, Dunmore JH, Fang Q, Berkemeier LR, Gu W, Kesterson RA, Boston BA, Cone RD, Smith J, Campfield LA, Burn P, Lee F: Targeted disruption of the melanocortin-4 receptor results in obesity in mice. Cell 1997;88:131-141.

8 Ho G, MacKenzie RG: Functional characterization of mutations in melanocortin-4 receptor associated with human obesity. J Biol Chem 1999;274:3581635822 .

9 Yeo GS, Lank EJ, Farooqi IS, Keogh J, Challis BG, O'Rahilly S: Mutations in the human melanocortin-4 receptor gene associated with severe familial obesity disrupts receptor function through multiple molecular mechanisms. Hum Mol Genet 2003;12:561-574.
0 Biebermann H, Krude H, Elsner A, Chubanov V, Gudermann T, Grüters A: Autosomal-dominant mode of inheritance of a melanocortin-4 receptor mutation in a patient with severe early-onset obesity is due to a dominant-negative effect caused by receptor dimerization. Diabetes 2003;52:2984-2988.

11 Schöneberg T, Schulz A, Biebermann H, Hermsdorf T, Römpler H, Sangkuhl K: Mutant G-proteincoupled receptors as a cause of human diseases. Pharmacol Ther 2004;104:173-206.

12 George SR, O’Dowd BF, Lee SP: G-protein-coupled receptor oligomerization and its potential for drug discovery. Nat Rev Drug Discov 2002;1:808-820.

13 Bouvier M: Oligomerization of G-protein-coupled transmitter receptors. Nat Rev Neurosci 2001;2: 274-286.

14 Hernanz-Falcon P, Rodriguez-Frade JM, Serrano A, Juan D, del Sol A, Soriano SF, Roncal F, Gomez L, Valencia A, Martinez-A C, Mellado M: Identification of amino acid residues crucial for chemokine receptor dimerization: Nat Immunol 2004;5:216-223. 
15 Filizola M, Weinstein H: Structural models for dimerization of G-protein coupled receptors: the opioid receptor homodimers: Biopolymers 2002;66: 317-325.

16 Kopanchuk S, Veiksina S, Mutulis F, Mutule I, Yahorava S, Mandrika I, Petrovska R, Rinken A, Wikberg JE: Kinetic evidence for tandemly arranged ligand binding sites in melanocortin 4 receptor complexes. Neurochem Int 2006;49: 533-542.

17 Elsner A, Tarnow P, Schaefer M, Ambrugger P, Krude H, Grüters A, Biebermann H: MC4R oligomerizes independently of extracellular cysteine residues. Peptides 2006;27:372-379.

18 Rettenbacher E, Tarnow P, Brumm H, Prayer D, Wermter AK, Hebebrand J, Biebermann H, Hinney A, Widhalm K: A novel non-synonymous mutation in the melanocortin-4 receptor gene (MC4R) in a 2-year-old Austrian girl with extreme obesity. Exp Clin Endocrinol Diabetes 2007;115:7-12.

19 Biebermann H, Schöneberg T, Krude H, Schultz G, Gudermann T, Grüters A: Mutations of the human thyrotropin gene causing thyroid hypoplasia and persistent congenital hypothyroidism: J Clin Endocrinol Metab 1997;82:3471-3480.

20 Schulz A, Grosse R, Schultz G, Gudermann T, Schöneberg T: Structural implication for receptor oligomerization from functional reconstitution studies of mutant V2 vasopressin receptors. J Biol Chem 2000;275:2381-2389.

21 Cherezov V, Rosenbaum DM, Hanson MA Rasmussen SG, Thian FS, Kobilka TS, Choi HJ, Kuhn P, Weis WI, Kobilka BK, Stevens RC: Highresolution crystal structure of an engineered human beta2-adrenergic G protein-coupled receptor. Science 2007;318:1258-1265.

22 Rasmussen SG, Choi HJ, Rosenbaum DM, Kobilka TS, Thian FS, Edwards PC, Burghammer M, Ratnala VR, Sanishvili R, Fischetti RF, Schertler GF, Weis WI Kobilka BK: Crystal structure of the human beta2 adrenergic G-protein-coupled receptor. Nature 2007;450:383-387.

23 Case DA, Pearlman DA, Caldwell JW, Cheatham TE III, Wang J, Ross WS, Simmerling CL, Darden TA, Merz KM, Stanton RV, Cheng AL, Vincent JJ, Crowley M, Tsui V, Gohlke H, Radmer RJ, Duan Y, Pitera J, Massova I, Seibel GL, Singh UC, Weiner PK, Kollman PA: AMBER 7. San Francisco, University of California, 2002
24 Laskowski RA, Moss DS, Thornton JM: Mainchain bond lengths and bond angles in protein structures. J Mol Biol 1993;231:1049-1067.

25 Dempfle A, Hinney A, Heinzel-Gutenbrunner M, Raab M, Geller F, Gudermann T, Schäfer H, Hebebrand J: Large quantitative effect of melanocortin-4 receptor gene mutations on body mass index. J Med Genet 2004;41:795-800.

$26 \mathrm{Gu}$ W, Tu Z, Kleyn PW, Kissebah A, Duprat L, Lee J, Chin W, Maruti S, Deng N, Fisher SL, Franco LS, Burn P, Yagaloff KA, Nathan J, Heymsfield S, Albu J, Pi-Sunyer FX, Allison DB: Identification and functional analysis of novel human melanocortin-4 receptor variants. Diabetes 1999;48:635-639.

27 Tarnow P, Schöneberg T, Krude H, Grüters A, Biebermann $\mathrm{H}$ : Mutationally induced disulfide bond formation within the third extracellular loop causes melanocortin 4 receptor inactivation in patients with obesity. J Biol Chem 2003;278:4866648673.

28 Hinney A, Hohmann S, Geller F, Vogel C, Hess C, Wermter AK, Brokamp B, Goldschmidt H, Siegfried W, Remschmidt H, Schafer H, Gudermann T, Hebebrand J: Melanocortin-4 receptor gene: case-control study and transmission disequilibrium test confirm that functionally relevant mutations are compatible with a major gene effect for extreme obesity. J Clin Endocrinol Metab 2003; $88: 4258-4267$.

29 Krude H, Biebermann H, Luck W, Horn R, Brabant G, Grüters A: Severe early-onset obesity, adrenal insufficiency and red hair pigmentation caused by POMC mutations in humans. Nat Genet 1998;19:155-157.

30 Krude H, Biebermann H, Schnabel D, Tansek MZ, Theunissen P, Mullis PE, Grüters A: Obesity due to proopiomelanocortin deficiency: three new cases and treatment trials with thyroid hormone and ACTH4-10. J Clin Endocrinol Metab 2003;88:46334640.

31 Farooqi IS, Keogh JM, Kamath S, Jones S, Gibson WT, Trussell R, Jebb SA, Lip GY, O'Rahilly S: Partial leptin deficiency and human adiposity. Nature 2001;414:34-35.

32 Kenakin T: Principles: receptor theory in pharmacology. Trends Pharmacol Sci 2004;25:186-192.
33 Palczewski K, Kumasaka T, Hori T, Behnke CA, Motoshima H, Fox BA, Le Trong I, Teller DC, Okada T, Stenkamp RE, Yamamoto M, Miyano M: Crystal structure of rhodopsin: A G proteincoupled receptor. Science 2000;289:739-745.

34 Salom D, Lodowski DT, Stenkamp RE, Le Trong I, Golczak M, Jastrzebska B, Harris T, Ballesteros JA Palczewski K: Crystal structure of a photoactivated deprotonated intermediate of rhodopsin. Proc Natl Acad Sci U S A 2006;103:16123-16128.

35 Standfuss J, Xie G, Edwards PC, Burghammer M, Oprian DD, Schertler GF: Crystal structure of a thermally stable rhodopsin mutant. J Mol Biol 2007:372:1179-1188.

36 Stäubert C, Tarnow P, Brumm H, Pitra C, Gudermann T, Grüters A, Schöneberg T, Biebermann H, Römpler H: Evolutionary aspects in evaluating mutations in the melanocortin 4 receptor. Endocrinology 2007;148:4642-4648.

37 Urizar E, Claeysen S, Deupi X, Govaerts C, Costagliola S, Vassart G, Pardo L: An Activation switch in the rhodopsin family of $G$ proteincoupled receptors: the thyrotropin receptor. J Biol Chem 2005;280:17135-17141.

38 Harrold JA, Widdowson PS, Williams G: BetaMSH: a functional ligand that regulated energy homeostasis via hypothalamic MC4-R? Peptides 2003;24:397-405.

39 Biebermann H, Castaneda TR, van Landeghem F, von Deimling A, Escher F, Brabant G, Hebebrand J, Hinney A, Tschop MH, Grüters A, Krude H: A role for beta-melanocyte-stimulating hormone in human body-weight regulation. Cell Metab 2006;3: 141-146.

40 Lee YS, Challis BG, Thompson DA, Yeo GS, Keogh JM, Madonna ME, Wraight V, Sims M, Vatin V, Meyre D, Shield J, Burren C, Ibrahim Z, Cheetham T, Swift P, Blackwood A, Hung CC, Wareham NJ, Froguel P, Millhauser GL, O'Rahilly S, Farooqi IS: A POMC variant implicates beta-melanocytestimulating hormone in the control of human energy balance. Cell Metab 2006;3:135-140.

41 Brock C, Schaefer M, Reusch HP, Czupalla C, Michalke M, Spicher K, Schultz G, Nürnberg B Roles of $\mathrm{G}$ beta gamma in membrane recruitment and activation of p110 gamma/p101 phosphoinositide 3-kinase gamma. J Cell Biol 2003;160:89-99. 